\title{
New Insights for the Management of Job Insecurity-Psychological Wellbeing Relationship
}

\author{
B. Piccoli and M. Bellotto
}

\begin{abstract}
Empirical evidence considers job insecurity as a stressor that leads to poor job-related well-being. With the present study we intend to increase this knowledge by testing how and through what mechanisms job insecurity may give rise to such consequences. In particular, we examined the mediating processes underlying the relationship between job insecurity and emotional exhaustion, as an indicator of psychological well-being and core element of burnout. A total of 322 blue collar workers in Italy are used to test the hypotheses derived from our framework. The results found support for a model in which the effect of job insecurity on exhaustion was mediated by two variables, i.e. breached psychological contract and perceived distributive injustice (three-path mediational model). Employees who were insecure perceived a breach of their psychological contract, which led to distributive injustice perceptions, which in turn increased emotional exhaustion. The tested model provides a theoretical framework that may lead to new insights on the job insecurity-burnout relationship.
\end{abstract}

Index Terms-Job insecurity, psychological contract breach, distributive justice, emotional exhaustion.

\section{INTRODUCTION}

Job insecurity is considered a topic particularly relevant and of increasing importance in this specific historical period Especially the economic crisis of recent years has led inevitably to lower financial security for organizations and less job security for their employees. Thus, job insecurity has become one of the most investigated job stressors of contemporary societies [1]. Numerous studies have documented its negative consequences on impaired wellbeing of the individual, like psychological distress or increased levels of emotional and physical exhaustion [2].

The view of job insecurity as a stressor that leads to strain and, hence, to poor job-related well-being, is shared by many authors and has found wide empirical evidence. With the present study, however, we want to increase this knowledge by understanding how and in what way job insecurity is associated with its consequences: these aspects still deserve additional attention in research. In particular, this research intends to focus on mechanisms that may explain the relationship between job insecurity and emotional exhaustion, as an indicator of psychological well-being. Emotional exhaustion is a component of Maslach's model of burnout [3] and is considered a typical stress reaction due a prolonged exposure to work demands. Exhaustion constitutes the core element of burnout. This dimension of employees'

Manuscript received August 12, 2014; revised November 19, 2014.

The authors are with the Department of Philosophy, Pedagogy and Psychology, University of Verona, Lungadige Porta Vittoria, 17, 37129 Verona, Italy (e-mail: beatrice.piccoli@univr.it). well-being appears relevant because it is predictive of various important work attitudes and behaviours [4].

Thus, the first contribution of this paper is to examine the underlying processes involved in translating perceptions of job insecurity into an individual consequence related to well-being, i.e. exhaustion: this could be a theoretical contribution that adds to our understanding of the nature of job insecurity. In particular, we propose a three-path mediational model with breach of psychological contract and organizational distributive injustice as two mediators (the one connected to the other) intervening in the relationship between job insecurity and burnout. In this manner, the proposed mechanisms refer to social exchange frameworks. In the present study we consider the perceptions of characteristics related to the exchange relationship between the individual and the organization, i.e. the psychological contract and organizational justice, to explain the underlying process of the job insecurity-strain association. Prior research has concentrated on perceptions at the individual level that contribute to strain, like the lack of personal job control or basic psychological need frustration. Focusing on factors related to the organizational exchange relationship in order to explain individual psychological well-being permits to identify variables on which management can intervene in order to modify (improve) this relationship. Thus, introducing theories related to social exchange frameworks also appears relevant from a practical point of view.

\section{THEORETICAL BACKGROUND}

\section{A. Job Insecurity and Emotional Exhaustion}

Job insecurity is considered a work stressor that generates stress reactions and reduces the psychological well-being of the individual. Several studies showed that feelings of job insecurity correlate with a lower score on various indicators of job-related well-being, like increased levels of mental, emotional and physical exhaustion, suggesting that a prolonged exposure to job insecurity can lead to a wearing out of individual resources [5]. Theoretical framework used for describing job insecurity in the stressor-strain relationship is the transactional stress theory. According to Lazarus and Folkman [6], stress perceptions and consequences are part of a dynamic process that consists of a primary and a secondary appraisal phase. Insecure employees perceive the threat of losing their job and it is not clear whether it will happen in the future (primary appraisal); moreover, an uncertain future makes it difficult to assess the coping strategies needed to solve the insecure situation (secondary appraisal). Thus, in the case of job insecurity, the appraisal process results in stress and strain because the demands of the situation are 
considered to exceed the accessible resources and no coping strategies appear to be effective.

In the present research, we intend to explain the relationship between job insecurity and emotional exhaustion, as a type of strain that results from workplace stressors. Emotional exhaustion is a component of Maslach's model of burnout. It is a chronic state of emotional and physical depletion. As Demerouti, Bakker, Nachreiner, and Schaufeli [7] suggested: "Emotional exhaustion closely resembles traditional stress reactions that are studied in occupational stress research, such as fatigue, job-related depression, psychosomatic complaints, and anxiety." It has emerged as a central variable for understanding the burnout process, for both empirical and conceptual reasons. Empirically, exhaustion exhibits stronger associations with important outcome variables than do the other components of burnout, e.g. depersonalization and diminished personal accomplishment. Conceptually, Shirom [8] stated that emotional exhaustion best captures the "core meaning" of burnout. This dimension of employees' well-being appears relevant because is predictive of various other aspects connected to work attitudes and behaviours: in fact, exhaustion was found to be related to organizational commitment, job performance, organizational citizenship behaviours and turnover intentions.

In the following section we introduce the hypothesized mechanisms to explain the relationship between job insecurity and exhaustion, going beyond previously proposed stress theories. The proposed route leading to the understanding of these mechanisms concerns theories of social exchange, i.e. psychological contract theory and organizational justice theory. Social exchange theories are one the most influential conceptual paradigms for understanding employees' reactions. They comprise a wide perspective that view relationships as generally characterized by the exchange of tangible or intangible resources (for a review, see Cropanzano \& Mitchell, 2005) [9]. Within organizational research, exchange relationships are commonly conceptualized as a mediator or intervening variable that determine workers' reactions. The psychological contract is considered part of this framework because it refers to individual beliefs or perceptions of the terms and conditions of the exchange relationship between the employee and his/her employer. Likewise, fair treatment can be considered a benefit to be reciprocated and represents a key source of information about the quality of the exchange relationship with the organization, because it signals to employees that their interests will be supported. The experience of justice engenders an obligation on the part of employees to reciprocate and thus fosters the development and maintenance of a social exchange relationship.

\section{B. Job Insecurity and Psychological Contract Breach}

In the literature, the psychological contract is described as the perceived mutual obligations between two parties, the employee and the employer. Specifically, Rousseau [10] distinguished three types of contracts that characterize the relationship between an individual and the organization: the formal contract (a written agreement), the implied contract (norms and values) and the psychological contract. The latter is implicit, informal and subjective. It consists of the duties and commitments that the employee perceives to have in the employment relationship as a response to rewards expected for the fulfillment of obligations and for being loyal to the employer. According to the exchange process underlying the psychological contract, the individual and the organization have expectations of each other regarding opportunities and behaviours. The individual expects to receive specific rewards from the organization; at the same time the organization places demands on the individual. One party's receipt of a benefit obligates the other party to reciprocate or return the favor: continued receipt and reciprocation create increasing obligations between the parties in an exchange relationship [11]. Within the psychological contract, the idea of balance is fundamental: a perceived imbalance between efforts and rewards results in the perception of a breach or even violation of the contract. In particular, psychological contract breach is the employee's perception regarding the extent to which the organization has failed to fulfill its promises or obligations.

The experience of job insecurity can lead to the perception of a breached psychological contract [12], because the individual considers secure employment as part of his or her implied agreement with the employer. Employees experience a threat to their terms of employment when they expect tenure in exchange for their work and loyalty. As noted in a recent study (De Cuyper \& De Witte, 2007) [13], a majority of the workforce still expects job security as a basic element that is part of the psychological contract and, accordingly, job insecurity represents a violation of this expectation. Breach of the psychological contract may give rise to negative reactions by the party experiencing this breach and may seriously impair the relationship. Research also suggests that psychological contract breach rather is the norm as opposed to an exception at work, particularly during times of organizational change and uncertainty. Thus, psychological contract theory defines job security as a key element of the psychological agreement adverse reactions could be related to an unwelcome change in the psychological contract, rather than to job insecurity per se. Therefore, we hypothesize:

Hypothesis 1: Job insecurity is positively related to perceptions of psychological contract breach.

\section{Distributive Justice and Its Relationship with \\ Psychological Contract Breach and Emotional Exhaustion}

Most of the research on the psychological contract has investigated the employees' reactions to unfulfilled organizational promises, i.e., contract breach. When employees perceive that their psychological contract has been breached, they feel a sense of both deception and betrayal that can have pervasive implications for the employee-employer relationship. Psychological contract breach has been linked to several negative employment outcomes and consequences, e.g. job dissatisfaction, intentions to leave, and poor in-role and extra-role behaviours. However, more recently, researchers have noted that the strength of the emotional and behavioral reactions that follow contract breach depend on how the employee cognitively assesses the organizational context related to the breach. Specifically, Robinson and Morrison (2000) [14] 
noted that, immediately following the perceptions of breach, individuals engage in a cognitive sense-making process through which they attempt to give meaning to the situation. In that interpretation process, employees evaluate not only the outcome itself, i.e. the presumed breach, but also why the event occurred. When individuals are faced with an unfavorable or unexpected outcome, they tend to seek explanations in order to determine the reasons for that outcome. These attributions have a strong effect on the intensity of emotions experienced. Another relevant component of this cognitive process involves the interpretation, immediately following the perception of contract breach, of how fairly the individual was treated. In particular, psychological contract breach may lead to distributive injustice perceptions because of the specific promises and outcomes that have been not fulfilled. Distributive justice refers to the allocation of rewards or resources to employee [15]. In the case of contract breach, individuals perceive that they do not receive the outcomes they deserve or were promised. This view is also in line with what Guest [16] argues about the state of psychological contract. According to him, when employees are considering whether expectations have been violated, they also evaluate the state of the contract. They not only evaluate the extent to which promises are kept, but also whether they are perceived as fair and whether they trust that the promises will be delivered in the future. Therefore, when the psychological contract is breached, the exchange is perceived as unfair. As fairness theory states, perceptions of injustice arise when individuals consider themselves as victims of a treatment that violates some moral principles (e.g. by breaking promises or expectations of the psychological contract). This framework incorporates the state of the psychological contract in terms of justice.

Therefore, considering the first hypothesis that relates job insecurity to breach of the psychological contract, the following is proposed:

Hypothesis 2: Breach of the psychological contract mediates the relationship between job insecurity and distributive justice.

Besides being related to psychological contract breach, distributive justice is also linked with emotional exhaustion. Wide empirical evidence suggests that employees' fairness perceptions are related to their attitudes and behaviours. Interestingly, research only recently explored whether organizational justice has implications for psychological well-being, despite parallels among constructs and processes identified in both the justice and stress literature [17]. In fact, fairness perceptions play a role in occupational stress-strain models and they have been associated with individual health and well-being. Preliminary empirical evidence shows that perceived unfairness is related to higher levels of burnout, self-reported mental health complaints, and sickness absence. Moreover, Elovainio, Kivimäki and Vahtera (2002) [18], have defined injustice as a "new psychosocial predictor of health". Unfairness has been conceptualized as a work stressor altering the balance between efforts and rewards and violating equity principle. In particular, distributive justice perceptions of employees are a function of the comparison between their outcome/input ratio and the outcome/input ratio of a referent other [19]. From an equity theory perspective, individuals try to find an equitable balance between what they receive from the organization and their own contributions. Empirical evidence about justice theory suggests that employees perceiving distributive injustice experience anger and a desire for recompense. Accordingly, unfavorable outcomes provide input to the primary appraisal process in the stress model that leads to strain. Distributive injustice, like inequitable pay raises or unfair distributions of workload, constitute what Lazarus and Folkman (1984) distinguished as a threat/harm to well-being. Moreover, the justice literature suggests that the consequences of an unequal distribution also include threats to employee's self-esteem and self-efficacy. Thus, people perceiving distributive injustice may feel that they lack the coping resources needed to solve the problem in the face of threats: this aspect (potential threat to self-efficacy) implies that distributive injustice plays a role in the secondary appraisal process. Therefore, to the extent that distributive injustice represents a threat/harm and determines the lack to cope adequately, employees will consider it as a stressor, which will in turn produce psychological distress or burnout. Furthermore, as Janssen and colleagues (2010) [20] suggested, distributive justice has especially strong effects on work related attitudes (e.g., pay satisfaction, job satisfaction), whereas procedural and interactional justice have strong effects on global attitudes about authority or the organization (e.g., organizational commitment). As emotional exhaustion is a specific and personally salient outcome of work, distributive justice seems particularly suitable to be considered as the justice dimension related to exhaustion.

Therefore, and considering the reasoning for the second hypothesis in which psychological contract breach relates to distributive injustice, the following is proposed:

Hypothesis 3: Distributive justice mediates the relationship between breach of the psychological contract and emotional exhaustion.

The role of breach of the psychological contract as intervening variable to explain the job insecurity-outcomes relationship has already been tested in other studies. For example, De Cuyper and De Witte (2007) [13] found that, among permanent workers, job insecurity was related to proximal and distal outcomes through the mediation by psychological contract breach. This study is innovative as we additionally consider the role of distributive justice. Justice theory is also part of the broader set of social exchange theories, just like psychological contract theory. In this study, we intend to combine both processes, and link both to one another, as it seems theoretically logical to link distributive inequity to breach of the psychological contract. Additionally, organizational justice has been found to have a direct effect on impaired psychological well-being (e.g. burnout). Therefore, we consider that a model that includes both psychological contract breach and distributive justice in a dual causal chain between job insecurity and emotional exhaustion will add to our understanding of this job insecurity-outcome relationship. 


\section{METHOD}

\section{A. Participants}

The survey was conducted in three plants of the same company located in the North-East of Italy. The organizations were paper mills and all employees involved $(N=322)$ were blue-collar workers, a category heavily affected by the economic crisis of recent years.

The sample was composed of $87.9 \%$ men and $12.1 \%$ women. The mean age was included in the range from 36 to 45 years $(39.7 \%)$. The majority of the participants $(65.2 \%)$ had an educational level from 9 to 13 years of school, corresponding to a secondary school degree. With regard to tenure, $54.7 \%$ of the participants had been working in the company for more than 10 years.

\section{B. Procedures}

The proposal of the project was explained to the head of the organization. After having obtained the agreement, workers union representatives were informed about the aim of the project. Questionnaires were administered in meetings organized during working hours, where the researcher explained how to fill them out and guaranteed confidentiality. Respondents were assured that there was no right or wrong answer and that they should answer all questions honestly.

\section{Measures}

Job insecurity was measured using 4 items focusing on the perceived probability of losing the current job and the worries related to that threat [21]. One example of the items used is: "I am sure I can keep my job" (reverse coded). Participants were asked to express their own agreement/disagreement with the items on a scale from 1 (= strongly disagree) to 5 (= strongly agree). The Cronbach's alpha of this scale was .81 .

Breach of the Psychological Contract. We used a global measure of perceived contract breach, which assessed employees' perceptions of how well their psychological contract had been fulfilled by their organizations. The measure contained the five items of the scale of Robinson and Morrison [22], with responses on a 1-5 scale ranging from "strongly disagree" to "strongly agree" $(\alpha=.85)$. Sample items are as follows: "I have not received everything promised to me in exchange for my contributions" and "Almost all the promises made by my employer during recruitment have been kept thus far" (reverse scored).

Distributive justice was measured with 5 items from Niehoff and Moorman [23], evaluating the fairness of different work outcomes, including pay level, work schedule, work load and job responsibilities (e.g., "I think that my level of pay is fair"). The response scale ranged from 1 (strongly disagree) to 5 (strongly agree). The scale reached a Cronbach alpha of .75.

Emotional exhaustion was measured with Maslach Burnout Inventory-General Survey (MBI-GS; Leiter \& Schaufeli, 1996) [24], a scale designed for assessing burnout in a wide range of occupations (outside the human service professions). The five items for emotional exhaustion refer to work-related feelings of fatigue, lack of energy and being unable to recover from work demands (e.g., "I feel emotionally drained because of my job"). The items were scored on a five-point scale ( $1=$ never; $5=$ always $)$. The reliability (Cronbach alpha) was .86 .

\section{Data Analysis}

The model derived from the mediated-effects hypotheses was tested using AMOS 17 [25]. Testing was done in two steps: (a) testing of the measurement model and (b) testing of the structural models. The first step related the observed variables to the underlying constructs by means of Confirmatory Factor Analysis (CFA). We tested and compared the hypothesized measurement model with two alternative models. The hypothesized model was a four-factor model in which all items loaded on the corresponding latent variable: job insecurity, psychological contract breach, distributive justice and emotional exhaustion. The alternative nested measurement models were (1) a one-factor model in which all items loaded on the same factor. In cross-sectional research common method variance can be a problem as the data in a single questionnaire can be closely related [26]. For this reason, the one factor model was tested. (2) A three-factor model: one factor for job insecurity and two latent factors representing the mediators (breach of the psychological contract and distributive justice together) and the outcome variable (emotional exhaustion) respectively. In every model, each of the observed variables loaded on only one latent factor and latent variables were allowed to correlate.

The fit of the models was evaluated using various indices: 1- the Non-Normed Fit Index (NNFI); 2- the Comparative Fit Index (CFI); 3- Root Mean Square Error of Approximation (RMSEA); 4- Standardized Root Mean Square Residual (SRMR); 5- Akaike Information Criterion (AIC) and Bayesian Information Criterion (BIC). The latter two indices are used to compare the fit of two or more models estimated from the same data set; lower values indicate a better fit. For NNFI and CFI values between .90 and .95 are acceptable. RMSEA and SRMR values indicate a good fit when they are smaller than or equal to .08. Competing models were also compared based on the chi-square difference test in addition to the fit indices.

Before testing the mediation hypotheses, we sought to identify the most appropriate structural model. Because we made no predictions as to whether the relationships in the model refer to partial or full mediation, we tested two competing models: a fully mediated model (Model 1) and a partially mediated model (Model 2, shown in Fig. 1). The partially mediated model differed from Model 1 in two direct paths from job insecurity to distributive justice and from psychological contract breach to emotional exhaustion. In addition, it specified a direct path from job insecurity to emotional exhaustion.

Bootstrapping was used to construct two-side bias corrected confidence intervals so as to evaluate mediation effects. As Hayes (2009) [27] suggests, bootstrapping is one of the more valid and powerful methods for testing intervening variable effects. Preacher and Hayes (2009) [27] recommend bootstrapping especially because it does not impose the assumption of normality of the sampling distribution. The statistical significance of bootstrap 
estimated indirect effects was evaluated: $95 \%$ bootstrap confidence intervals (5000 samples) for indirect effects were computed to evaluate whether they included zero.

\section{RESUlts}

\section{A. Descriptive Statistics}

Descriptive statistics of the scales (means and standard deviations), Bravais-Pearson's ' $r$ ' correlations between the variables and Cronbach's alphas are reported in Table I. As expected, the correlation matrix showed that job insecurity was positively correlated to both breach of the psychological contract and emotional exhaustion, and negatively correlated to distributive justice. Furthermore, psychological contract breach was negatively associated with distributive justice and positively with emotional exhaustion. Finally, distributive justice was negatively correlated with emotional exhaustion.

TABLE I: MEANS, STANDARD DEVIATIONS, RELIABILITIES (CRONBACH'S ALPHA) AND CORRELATIONS AMONG THE VARIABLES

\begin{tabular}{lccllll}
\hline Variable & M & SD & 1 & 2 & 3 & 4 \\
\hline 1. Job Insecurity & 2.12 & .82 & $(.81)$ & & & \\
2. Distributive Justice & 3.09 & .81 & $-.50^{* *}$ & $(.75)$ & & \\
3. Psychological Contract & 2.32 & .88 & $.47^{* *}$ & $-.66^{* *}(.85)$ & \\
4. Emotional Exhaustion & 2.52 & .82 & $.48^{* *}$ & $-.60^{* *}$ & $.45^{* *}$ & $(.86)$ \\
\hline
\end{tabular}

Note: $*_{P}<.05 ; * * P<.01 ; * * * P<.001$

\section{B. Measurement Model}

The hypothesized measurement model with four latent variables (job insecurity, breach of the psychological contract, distributive justice and emotional exhaustion) provided a good fit to the data: $\chi_{(146)}^{2}=342.6 ; \mathrm{NNFI}=.93 ; \mathrm{CFI}=.94$; RMSEA $=.06$ with C.I $=.052-.060 ;$ SRMR $=.05$. All items loaded significantly on their corresponding latent factors, ranging from .55 to .92 . The competing models were (1) a one-factor model $\left(\chi_{(152)}^{2}=1111.8, p<.001\right)$ and (2) a three-factor model $\left(\chi_{(149)}^{2}=466.4, p<.001\right)$. None of these alternative models reached the threshold acceptable for all fit indices (see Table II.).

TABLE II: CONFIRMATORY FACTOR ANALYSES FOR THE MEASUREMENT MODELS

\begin{tabular}{|c|c|c|c|c|c|c|c|}
\hline Model & $\chi^{2}$ & $D f$ & $p$ & NNFI & CFI & $\begin{array}{l}\text { RMSEA } \\
\text { (C.I.) }\end{array}$ & SRMR \\
\hline $\begin{array}{l}\text { Four - factor model } \\
\text { (hypothesized model) }\end{array}$ & 342.6 & 146 & $<.001$ & .93 & .94 & $(.052-.070)$ & .05 \\
\hline One - factor model & 1111.8 & 152 & $<.001$ & .63 & .67 & $(.133-.148)$ & .10 \\
\hline Three-factor model & 466.4 & 149 & $<.001$ & .87 & .88 & $\begin{array}{c}.08 \\
(.073-.090)\end{array}$ & .08 \\
\hline
\end{tabular}

\section{Structural Model}

Before testing our hypotheses, we needed to identify the most appropriate structural model. Because we made no prediction as to whether the relationships in the model represented partial or full mediation, we followed the recommendation of James, Mulaik, and Brett (2006) [28] according to which the full mediation model represents the best choice of a baseline model. Thus, we compared the fit of this model (Model 1) with that of an alternative partial mediation model (Model 2). The full mediation model included three paths, from the antecedent variable (JI) to the first mediator (BPC), from this to the second mediator (DJ) and from latter to the outcome variable (EE). Therefore, it assumes that the effect of the antecedent variable on the outcome variable is exerted indirectly, through both mediators. Fit indices of this full mediation model provided an acceptable fit to the data: $\chi_{(149)}^{2}=387.7$; NNFI $=.92$, $\mathrm{CFI}=.93$, RMSEA $=.07$ (C.I $=.061-.078), \mathrm{SRMR}=.08$. The partial mediation model added three paths to this model, connecting JI to both DJ and EE, and a direct path from BPC to EE. Also this model provided an good fit to the data: $\chi_{(146)}^{2}$ $=314.3 ; \mathrm{NNFI}=.94, \mathrm{CFI}=.95, \mathrm{RMSEA}=.06$ (C.I. $=.051$ - .069), SRMR= .05. However, on the basis of chi-square difference the results showed that the partially mediated model had a better fit than the fully mediated model $\left(\Delta \chi_{(3)}^{2}=\right.$ $73.4, p<.001)$. Furthermore, also the values of AIC and BIC for the partial mediation model were smaller (full model: $\mathrm{AIC}=460.696, \mathrm{BIC}=615.453$; partial model: $\mathrm{AIC}=402.316$, $\mathrm{BIC}=568.396)$. Therefore, we retained Model 2 as the preferable model and used it to examine our mediation hypotheses. Model 2 is presented in Fig. 1 with the estimates among the variables.

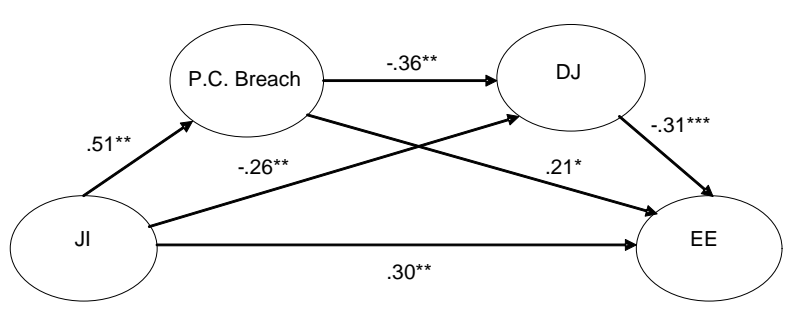

Fig. 1. Model 2 (partial mediation model) with standardized path coefficients.

All standardized path coefficients of this model (shown in Figure 1), were statistically significant (either at $p<.001$ or at $p<.01)$ and in the predicted direction. Specifically, the path running from job insecurity to psychological contract breach was positive and statistically significant $(\beta=.51, p<.001)$, supporting Hypothesis 1 . The model explained $26 \%$ of the variance in psychological contract breach. Moreover, the path coefficient from psychological contract breach to distributive justice was negative and statistically significant $(\beta=-.36, p<.001)$. The model explained $30 \%$ of variance in distributive justice. In turn, distributive justice exerted a negative significant effect on emotional exhaustion $(\beta=-.31$, $p<.001)$. The exhaustion variability explained from the model was $43 \%$. In addition, job insecurity exerted a negative significant effect on distributive justice $(\beta=-.26, p<.001)$ and a positive significant effect on emotional exhaustion $(\beta$ $=.30, p<.001)$. Finally, there was a significant effect from psychological contract breach and emotional exhaustion $(\beta$ $=.21, p<.01)$ Hypotheses 2 and 3 predicted that breach of the psychological contract and distributive justice are two mediators intervening in the causal chain between job 
insecurity and emotional exhaustion. In order to test the mediating role, we examined the significance of each indirect effect with the bootstrapping method, as recommended by Hayes (2009) [27]. In support to Hypothesis 2, the results showed that job insecurity had a significant indirect association, via breach of the psychological contract, with distributive justice (standardized indirect effect $=-.18,95 \%$ $\mathrm{CI}=-.27,-.11)$. In addition, psychological contract breach also had a significant indirect association, via distributive justice, with emotional exhaustion (standardized indirect effect $=.11,95 \% \mathrm{CI}=.13, .27$ ), which offers support for Hypothesis 3.

\section{DISCUSSION}

The present article tested a model of the effects of job insecurity on psychological well-being. We hypothesized that the effects of job insecurity on this outcome would be mediated by psychological contract breach and distributive justice perceptions, two mediators acting on each other (three-path mediational model). The results provide clear support for a model where the two hypothesized mediators partially mediate the relationship between job insecurity and emotional exhaustion, the core element of burnout.

Many studies have focused on poor psychological well-being as a consequence of job insecurity, but very little research examined the underlying processes to explain this relationship. Consequently, the present research adds to the literature because it proposed psychological contract breach and distributive justice in a three-path model as mediating mechanisms through which job insecurity is related to burnout. The mediational role of psychological contract breach on consequences associated with job insecurity has already been tested in other studies. For example, De Cuyper \& De Witte (2007) [13], found that among permanent workers the fulfillment of psychological contract entitlements mediated the relationship between proximal and distal outcomes of job insecurity. However, our article extends previous research by also examining the role of distributive justice as explanatory variable in the same causal chain. This has the advantage of simultaneously testing both theories against each other in the same model. As Preacher and Hayes (2009) [27] suggest, there are several advantages to examining a multiple mediation model instead of separate simple mediation models. For example, it is possible to determine to what extent specific intervening variables mediate the effect of the independent on the dependent variable, conditional on the presence of other mediators in the model. Moreover, when more than one mediator is included in the model, the likelihood of parameter bias due to omitted variables is reduced.

In addition, considering psychological contract breach and distributive justice we proposed mechanisms referred to a social exchange framework to explain the relationship between job insecurity and burnout. The psychological contract is part of this framework because it represents the expectations or beliefs held by an employee about the reciprocal obligations that comprise the employeeorganization exchange relationship. Also the perception of fair treatment is a key source about the quality of the relationship with the organization, because it signals to employees that their interests will be supported. Therefore, these mediators may be considered as two key factors for a social exchange explanation of the conditions that translate feelings of job insecurity in a psychological manifestation of distress.

\section{A. Theoretical and Practical Implications}

The results of this study have both theoretical and practical implications. By integrating psychological contract theory and distributive justice theory in a three-path mediational model, we examined the relationships between job insecurity and psychological well-being. Theoretically, we found that both variables are interrelated and help in identifying different mechanisms that determine psychological reactions to job insecurity. These theories are part of the broader social exchange framework because they emphasize the reciprocal obligations between two parties (employee and employer) in the relationship. According to this framework, reciprocal interdependence determines contingent interpersonal transactions, whereby an action by one party leads to a response by another. If a person supplies a benefit, the receiving party should respond in kind [9]. Therefore, psychological contract breach and distributive injustice may "disturb" the balance between efforts and rewards and consequently may violate the principles of equity: for this reason they can be interpreted as work stressors determining reduced well-being. Thus, the employment exchange relationship may play a role in worker's experience of job strain. Accordingly, this research can provide theoretical contributions that add to our understanding of the nature of job insecurity: our attempt has been to explain the mediational process by means of social exchange theory.

In practical terms, it is noteworthy to point out that in uncertain work situations the perceptions of psychological contract and distributive justice become particularly important in determining psychological outcomes related to job insecurity. This means that organizations need to be careful about what they promise and regarding allocation of outcomes, especially during periods of uncertainty. For example, even if promises about the psychological contract are made in good faith, managers may not be able to fulfill them at a later point in time if conditions are uncertain. In order to reduce perceptions of psychological contract breach and their negative correlates, organizations may consider to increase the amount of contact and communication between organizational agents and employees [14].

On the other hand, also principles of equity and a balance of exchange in order to enhance fairness may play an important role in uncertain circumstances. Specifically, the results suggest that managers should be particularly attentive to employees' perceptions of distributive justice in the face of insecure situations. Social comparison with relevant others may occur particularly in a workforce that is affected by job insecurity [29]. Thus, organizations need to create a work environment where employees are fairly recompensed for the resource investments they put into their job. The greater the threat to job loss, the more important it is for managers to take actions that increase, maintain or restore employees' distributive justice perceptions. 


\section{REFERENCES}

[1] H. D. Witte, N. D. Cuyper, E. V. Elst, E. Vanbelle, and W. Niesen, "Job insecurity: Review of the literature and a summary of recent studies from Belgium," Romanian Journal of Applied Psychology, vol. 14, no. 1, pp. 11-17, 2012.

[2] G. H.-L. Cheng and D. K.-S. Chan, "Who suffers more from job insecurity? A meta-analytic review," Applied Psychology: An International Review, vol. 57, pp. 272-303, 2008.

[3] C. A. Maslach and M. P. Leiter, "Early predictors of job burnout and engagement," Journal of Applied Psychology, vol. 93, pp. 498-512, 2008.

[4] R. Cropanzano, D. E. Rupp, and Z. S. Byrne, "The relationship of emotional exhaustion to work attitudes, job performance, and organizational citizenship behaviors," Journal of Applied Psychology, vol. $88,160-169,2003$.

[5] S. Dekker and W. Schaufeli, "The effects of job insecurity on psychological health and withdrawal: A longitudinal study," Australian Psychologist, vol. 30, pp. 57-63, 1995.

[6] R. S. Lazarus and S. Folkman, Stress, Appraisal, and Coping, New York: Springer Publishing Company, 1984.

[7] E. Demerouti, A. B. Bakker, F. Nachreiner, and W. B. Schaufeli, "The job demands-resources model of burnout," Journal of Applied Psychology, vol. 86, pp. 499-512, 2001

[8] A. Shirom, "Burnout in work organizations," in International review of industrial-organizational psychology, C. L. Cooper and I. Robertson, Eds., New York: Wiley, pp. 25-48, 1989.

[9] R. Cropanzano and M. S. Mitchell, "Social exchange theory: An interdisciplinary review," Journal of Management, vol. 31, pp. 874-900, 2005

[10] D. M. Rousseau, Psychological Contract in Organizations: Understanding Written and Unwritten Agreements, Thousand Oaks, CA: Sage, 1995.

[11] P. M. Blau, Exchange and Power in Social Life, New York: Wiley, 1964.

[12] N. D. Cuyper and H. D. Witte, "The impact of job insecurity and contract type on attitudes, well-being and behavioural reports. A psychological contract perspective," Journal of Occupational and Organizational Psychology, vol. 79, pp. 395-409, 2006.

[13] N. D. Cuyper and H. D. Witte, "Exploring the new psychological contract among temporary and permanent workers: Associations with attitudes, behavioural intentions and well-being," in Occupational Health Psychology, European Perspectives on Research, Education and Practice, S. McIntyre and J. Houdmont, eds., Maia, Portugal: ISMAI Publishers, pp. 59-79, 2007.

[14] S. L. Robinson and E. W. Morrison, "The development of psychological contract breach and violation: a longitudinal study," Journal of Organizational Behavior, vol. 21, pp. 525-546, 2000.

[15] B. P. Niehoff and R. H. Moorman, "Justice as a mediator of the relationship between methods of monitoring and organizational citizenship behavior," Academy of Management Journal, vol. 36, pp. 527-556, 1993.

[16] D. Guest, "Flexible employment contracts, the psychological contract and employee outcomes: An analysis and review of the evidence," International Journal of Management Reviews, vol. 5, no. 6, pp. 1-19, 2004.

[17] J. M. Robbins, M. T. Ford, and L. E. Tetrick, "Perceived unfairness and employee health: A meta-analytic integration," Journal of Applied Psychology, vol. 97, pp. 235-271, 2012.

[18] M. Elovainio, M. Kivimäki, and J. Vahtera, "Organizational justice: evidence of a new psychosocial predictor of health," American Journal of Public Health, vol. 92, pp. 105-108, 2002.

[19] J. S. Adams and S. Freedman, "Equity theory revisited: Comments and an annotated bibliography," in Equity theory: Toward a general theory of social interaction, L. Berkowitz and E. Walster, Eds., New York: Academic Press, pp. 43-90, 1976.

[20] O. Janssen, C. K. Lam, and A. X. Huang, "Emotional exhaustion and job performance: The moderating roles of distributive justice and positive affect," Journal of Organizational Behavior, vol. 31, pp. 787-809, 2010.

[21] T. V. E. V. Elst, H. D. Witte, and N. D. Cuyper, "The job insecurity scale: A psychometric evaluation across five European countries," European Journal of Work and Organizational Psychology, vol. 23, no. 3, pp. 364-380, 2014.

[22] S. L. Robinson and E. W. Morrison, "The development of psychological contract breach and violation: a longitudinal study," Journal of Organizational Behavior, vol. 21, pp. 525-546, 2000.

[23] B. P. Niehoff and R. H. Moorman, "Justice as a mediator of the relationship between methods of monitoring and organizational citizenship behavior," Academy of Management Journal, vol. 36, pp. 527-556, 1993.

[24] M. P. Leiter and W. B. Schaufeli, "Consistency of the burnout construct across occupations," Anxiety, Stress, and Coping, vol. 9, pp. 229-243, 1996.

[25] J. L. Arbuckle, AMOS 17 User's Guide, Chicago: SPSS Inc, 2008.

[26] P. M. Podsakoff, S. B. MacKenzie, J. Y. Lee, and N. P. Podsakoff, "Common method biases in behavioral research: a critical review of the literature and recommended remedies," Journal of Applied Psychology, vol. 88 , pp. 879-903, 2003

[27] K. J. Preacher and A. F. Hayes, "Asymptotic and resampling strategies for assessing and comparing indirect effects in multiple mediator models," Behavior Research Methods, vol. 40, no. 3, pp. 879-891, 2008.

[28] L. R. James, S. A. Mulaik, and J. M. Brett, "A tale of two methods," Organizational Research Methods, vol. 9, pp. 233-244, 2006.

[29] J. Pfeffer, "Human resources from an organizational behavior perspective: some paradoxes explained," Journal of Economic Perspectives, vol. 21, pp. 115-134, 2007.

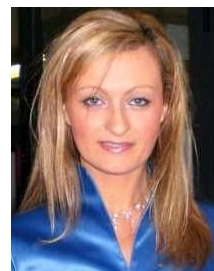

Beatrice Piccoli received her Ph.D. from the Katholieke Universiteit of Leuven (Belgium). Currently she is a researcher associate in work and organizational psychology and expert in Psychometrics at the University of Verona, Italy. Her main research interests concern antecedents and consequences of job insecurity.

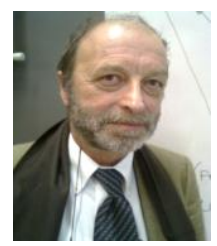

Massimo Bellotto is a full professor in work and organizational psychology at the University of Verona, Italy. His studies and publications focus mainly on the theoretical and methodological aspects of the psycho-social training, organizational cultures and work values related to personal and professional development. 